\title{
Rubber glove tourniquet: perhaps not so simple or safe?
}

\author{
H. L. de Boer $\cdot$ P. Houpt
}

Received: 7 January 2007 / Accepted: 18 January 2007 / Published online: 22 June 2007

(C) Springer-Verlag 2007

\begin{abstract}
A bloodless field is essential in hand surgery. In finger surgery, this can be achieved by the rubber glove technique. When treating a tip avulsion in a 5-year-old boy the tourniquet was accidentally left in place. This resulted in a necrotic finger that had to be amputated. To prevent this disastrous complication, we propose never to use this method of digital tourniquet.
\end{abstract}

Keywords Finger - Glove · Tourniquet · Complication

\section{Introduction}

A bloodless field is deemed essential in hand surgery, and the use of a tourniquet is a well-established practice. Tourniquets can be placed around the upper limb, and when operating on a single finger, they can be placed around the base of a finger. When operating under local anaesthesia, a digital tourniquet, when applicable, is preferred. The reason for this is because patients cannot tolerate the pressure of an upper limb tourniquet for a long period. Several types of digital tourniquets are in use. The rubber glove method [1] is reportedly a simple, safe and elegant method. A normal operating glove, which is cheap, sterile and always available, is used. A gloved finger is cut and the tip of the gloved finger removed. This is placed over the finger to be operated upon. As the glove is rolled proximally, the finger is exsanguinated, and a digital

An invited commentary on this paper is available at doi: $10.1007 /$ s00238-007-0145-7.

H. L. de Boer $(\varangle) \cdot$ P. Houpt

Department of Plastic Surgery, Isala Klinieken,

Postbus 10400, 8000 GK Zwolle, The Netherlands

e-mail: luitzendeboer@hotmail.com tourniquet around the base of the finger is achieved. This seems to be a simple and ideal method.

\section{Case report}

A 5-year-old boy presented to the emergency department of our hospital; his middle finger of the left hand had been caught in a door. This resulted in a tip avulsion with exposed bone and a laceration of the germinal nail matrix. $\mathrm{He}$ had eaten $1 \mathrm{~h}$ before the accident. Because the patient was very cooperative, it was decided to do the operation under local anaesthesia; the rubber glove tourniquet method was used. After a soft tissue and germinal matrix repair, a dressing was applied, and the boy was sent home. The first 2 days were uneventful, but on the third and fourth days, increasing soreness was noted. The patient was seen on day 5 on routine postoperative control; it was only then that the forgotten tourniquet was first noticed. The entire finger was necrotic (Fig. 1) and had to be amputated. The parents and patient, the hospital complication board and the national health inspection were informed.

\section{Discussion}

Inadvertently leaving the tourniquet in place is a wellknown risk [2, 3]. We have tried to determine any mitigating circumstances which might have caused this complication. The surgeon, who was in his final year of plastic surgery residency, was well aware of this risk. He was experienced both in performing this procedure and this type of digital tourniquet. The patient was relaxed and cooperative. The room where the operation took place was quiet, and there were no distractions. There were no other 


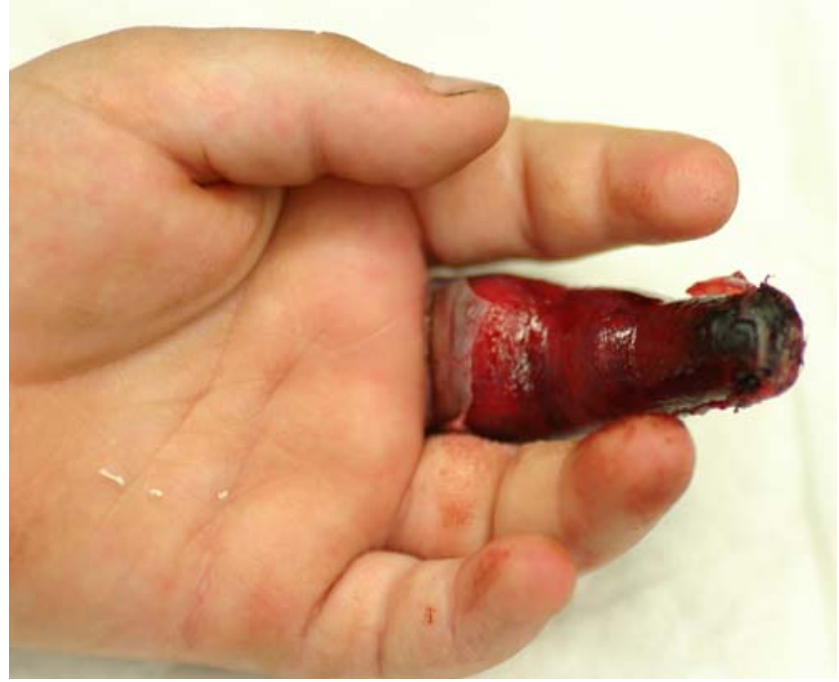

Fig. 1 Necrotic middle finger of a 5-year-old boy with the forgotten tourniquet

procedures planned that day. Present during the procedure were a junior intern, a nurse and the boy's mother. During the procedure, the risk of leaving the tourniquet was discussed with all present, and everyone was asked to remind the surgeon to remove the tourniquet.

After the operation, the finger was still numb from the local anaesthesia. Nerves are the first structures in the digit to become damaged by the pressure of the tourniquet. This is how a "painless" ischemia can occur even when the effects of the local anaesthesia wear off.

\section{Conclusion}

The consequences of leaving a digital tourniquet are dramatic. This has occurred in our department despite being well aware of the risk. No cause could be identified as to how this could have happen.

Our advice is to only use a tourniquet that has to be closed using a large clamp. That way, inadvertently putting a dressing over the tourniquet becomes impossible.

\section{References}

1. Barnett A, Pearl RM (1983) Readily available, inexpensive finger tourniquet. Plast Reconstr Surg 71(1):134-135

2. Karabagli Y, Kose AA, Cetin C (2005) Toe necrosis due to a neglected tourniquet. Plast Reconstr Surg 116(7):2036-2037; author reply 2037-2038

3. Smith IM, Austin OMB, Knight SL (2002) A simple and fail safe method for digital tourniquet. J Hand Surg [Br] 27(4):363-364 (review) 